\title{
COL2A1 and Caspase-3 as Promising Biomarkers for Osteoarthritis Prognosis in an Equus asinus Model
}

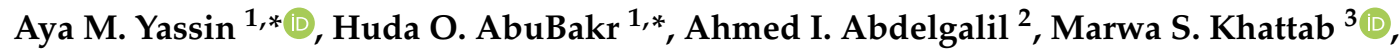 \\ Adel M. EL-Behairy ${ }^{1}$ and Eman M. Gouda ${ }^{1}$ \\ 1 Department of Biochemistry and Chemistry of Nutrition, Faculty of Veterinary Medicine, Cairo University, \\ Giza 12211, Egypt; adelelbehairy@cu.edu.eg (A.M.E.-B.); eman_gouda@cu.edu.eg (E.M.G.) \\ 2 Department of Surgery, Anesthesiology and Radiology, Faculty of Veterinary Medicine, Cairo University, \\ Giza 12211, Egypt; ismael7591@cu.edu.eg \\ 3 Department of Pathology, Faculty of Veterinary Medicine, Cairo University, Giza 12211, Egypt; \\ marwakhattab@cu.edu.eg \\ * Correspondence: ayamohye@cu.edu.eg (A.M.Y.); huda.omar@cu.edu.eg (H.O.A.)
}

Received: 4 December 2019; Accepted: 21 February 2020; Published: 26 February 2020

\begin{abstract}
Osteoarthritis (OA) is one of the most degenerative joint diseases in both human and veterinary medicine. The objective of the present study was the early diagnosis of OA in donkeys using a reliable grading of the disease based on clinical, chemical, and molecular alterations. OA was induced by intra-articular injection of $25 \mathrm{mg}$ monoiodoacetate (MIA) as a single dose into the left radiocarpal joint of nine donkeys. Animals were clinically evaluated through the assessment of lameness score, radiographic, and ultrasonographic findings for seven months. Synovial fluid and cartilage samples were collected from both normal and diseased joints for the assessment of matrix metalloproteinases (MMPs) activity, COL2A1 protein expression level, and histopathological and immunohistochemical analysis of Caspase-3. Animals showed the highest lameness score post-induction after one week then decreased gradually with the progression of radiographical and ultrasonographic changes. MMP activity and COL2A1 and Caspase-3 expression increased, accompanied by articular cartilage degeneration and loss of proteoglycan. OA was successfully graded in Egyptian donkeys, with the promising use of COL2A1and Caspase-3 for prognosis. However, MMPs failed to discriminate between early and late grades of OA.
\end{abstract}

Keywords: osteoarthritis; donkey; matrix metalloproteinases; COL2A1; Caspase-3

\section{Introduction}

Osteoarthritis (OA) is one of the most difficult chronic slowly progressive degenerative joint diseases in both human and veterinary medicine [1-3]. This disease mainly causes pain, lameness, and alterations in animal quality of life and welfare [4]. The equine industry attracts great attention, as the horse racing industry is worth over $£ 3.45$ billion to the UK economy and economic loss to this industry refers to diagnosed OA [5].

The etiology of OA is not well known, and its progression mainly alters articular cartilage homeostasis, which is avascular tissue with limited regenerative ability. The mechanical support and joint lubricant proprieties of articular cartilage are dependent on the integrity of its extracellular matrix (ECM) [6]. Cartilage ECM is rich in fibrillar collagens, especially type II, that occupy $80 \%$ of total collagen, large proteoglycans, and smaller hydrophilic macromolecules [7]. In normal physiological conditions, chondrocytes regulate the structural and functional integrity of cartilage through maintaining the equilibrium between the synthesis and degradation of the ECM components [8], while in OA, the cardinal surgical signs are characterized by progressive loss of articular cartilage, 
concurrently with reactive responses in the joint as subchondral osteoblast activation, osteophytes formation, and synovitis [9]. Additionally, histobiochemical analysis of OA attributes a change in proteoglycan metabolism and ECM loss that is easily evidenced by reduced Safranin-O staining [10].

The pathophysiology of $\mathrm{OA}$ is characterized by the launching of proinflammatory cytokines, such as interleukin-1 $\beta$ (IL-1 $\beta$ ) and tumor necrosis factor- $\alpha$ (TNF- $\alpha$ ); subsequently, cartilage degrades through two phases: the degradative and biosynthetic phase. In the degradative phase, proteolytic enzymes, including matrix metalloproteinases (MMPs) and the A Disintegrin and Metalloproteinase domain with Thrombospondin-like motifs family (ADAMTS), digest the ECM, accompanied by repairing the damaged cartilage in the biosynthetic phase $[11,12]$. However, matrix synthesis is rapidly inhibited by inflammatory factors through the down regulation of ECM genes with accelerating cartilage damage [13]. The major MMPs involved in the digestion of the ECM include the interstitial collagenases (MMP-1, MMP-8, MMP-13), gelatinases (MMP-2 and MMP-9), stromelysin 1 (MMP-3), and membrane-type collagenases (MMP-14 and MMP-16) [14]. In normal conditions, chondrocytes express MMP-1, MMP-8, and MMP-13 at low levels, whereas these enzymes were found to be expressed 10-fold higher in osteoarthritic joints, resulting in the digestion of cartilage collagen, which is considered a critical step in the loss of articular cartilage [15]. Recently, several studies have proved the correlation between cell death and matrix degradation of human and animal OA cartilage models [16-18], since matrix degradation results in the loss of survival mechanisms [19], calcification [20], and apoptosis [21]. Cartilage or chondrocyte apoptosis is mediated by a cascade of aspartate-specific cysteine proteases or several types of caspases, especially Caspase- 3 which is one of the key mediators of apoptotic executioners in its execution phase [22].

Animal models are standard research tools for studying the pathogenesis, diagnosis, and powerful therapeutic intervention of different diseases [23,24]. The slowly progressive nature of OA necessitates certain criteria for the selection of appropriate animal models in OA studies, such as anatomical features of articular cartilage, long life, and the availability of collection of synovial fluid samples $[25,26]$. From all animal models, those which have articular cartilage closest to humans are equine species [27-29]. Several studies have been elucidated to study OA in horses, especially since they are good models for naturally occurring OA to rescue the horse racing industry and attract attention to human OA [30,31]. Donkey (Equus asinus) is one of the equine species and closest animal to the horse, making this species an alternative cheap animal model for studying equine diseases [32-34].

Experimental models of chemically induced OA using intra-articular injection of monoiodoacetate (MIA) were reported in rat [35], rabbit [36], pig [37], and horse [38,39].

The absence of real and effective treatment able to reverse the progressive changes of OA and the lack of adequate diagnostic tools brings out the need to develop early biomarkers for rapid medical intervention and achieve a good prognosis. Thus, the challenge of the present study is the early diagnosis of $\mathrm{OA}$ in donkeys using a reliable grading of the disease based on clinical, chemical, and molecular alterations. For achieving this purpose, OA in donkeys is induced chemically by MIA injection and the disease grading is followed up by X-ray and ultrasonography, monitoring the biochemical and molecular changes using the synovial fluid as a mirror for the joint environment.

\section{Materials and Methods}

\subsection{Ethical Statement}

This animal experiment followed the guidelines developed by the American Psychological Association (APA) for the ethical conduct of care and use of animals and approval was obtained from CU-IACUC with No. (CU/II/F/4/16).

\subsection{Animals}

Nine adult male donkeys aged 3-5 years, weighing 150-200 kg, of a healthy Egyptian local breed were subjected to comprehensive orthopedic examination, including an assessment of lameness 
during walking and trotting in straight lines and circles on hard ground [40,41]. The radiographical examination of the radiocarpal joints of both limbs and range of motion of joints (angle of flexion) were assessed to ensure that they were within normal limits and only animals proven healthy were selected for the present study.

\subsection{Housing and Feeding}

Animals were housed in an isolated and well-ventilated stable under standard environmental conditions $\left(23 \pm 1{ }^{\circ} \mathrm{C}, 55 \pm 5 \%\right.$ humidity, and $12 \mathrm{~h}$ light/dark cycle) at the Department of Surgery and anesthesiology, Faculty of Veterinary Medicine, Cairo University, Giza, Egypt. All donkeys were given free access to water and were given well-balanced rations. Donkeys were allowed to acclimatize for two weeks before the study. During the acclimatization period, animals were trained daily to familiarize them with the experimental conditions (investigators, environment, handling, vein puncture, and various outcome measures) and were walking daily for 15-20 min.

\subsection{Study Design}

\subsubsection{Control Sample Collection}

At the beginning of the experiment, synovial fluid samples were collected from the left radiocarpal joint of all nine adult donkeys before osteoarthritis induction (day 0).

\subsubsection{Induction of Osteoarthritis}

Under strict aseptic conditions, the left radiocarpal joint in each donkey was intra-articularly injected with $25 \mathrm{mg}$ of MIA (sodium monoiodoacetate, Sigma-Aldrich, St. Louis, MO, USA) dissolved in $1 \mathrm{~mL}$ of sterile saline [34].

\subsection{Clinical Assessment}

\subsubsection{Evaluation of Lameness}

Evaluation of lameness was done following the American Association of Equine Practitioners (AAEP) scale for lameness evaluation [23]: $0=$ sound, $1=$ lameness difficult to detect and inconsistent, 2 = lameness difficult to detect, but consistent, $3=$ lameness consistently detectable on a straight line, and $4=$ obvious lameness with marked head nodding [33].

\subsubsection{Radiographical Examination}

X-ray films of the radiocarpal joints were taken weekly starting from day 0 (before MIA injection) to the end of the experiment (seven months). The radiographs were taken in dorso-palmar and latero-medial views. The settings of the X-ray machine were $50 \mathrm{KV}, 3 \mathrm{mAs}$, and $75 \mathrm{~cm}$ focal film distance. The degree of arthritic changes was scored according to the Osteoarthritis Research Society International (OARSI) classification of osteoarthritis of the knee [42].

\subsubsection{Ultrasonographic Procedures}

The dorsal surface of the carpal region was clipped and shaved in all animals. Ultrasonographic examinations were performed using a Toshiba Just Vision 200 (Japan) machine equipped with $10 \mathrm{MHz}$ linear probe. The probe was positioned along the length and width of the radio-carpal joint in the flexed position. Synovial fluid and articular cartilages were evaluated on day 0 , one, two, three, five, and seven months after induction. 


\subsection{Experiments}

\subsubsection{Sample Collection}

\section{Synovial Fluid Collection}

Samples (about $1 \mathrm{~mL}$ ) were collected from the left radiocarpal joint of each animal under complete aseptic conditions using a 23G needle before any interference at day 0 , then weekly post-injection until the end of the study at seven months. Three donkeys were randomly euthanized at three, five, and seven months for cartilage sample collection. The collected samples were immediately centrifuged at $10,000 \times \mathrm{g}$ for $20 \mathrm{~min}$ at $4{ }^{\circ} \mathrm{C}$. The supernatants were aliquoted and stored at $-20{ }^{\circ} \mathrm{C}$ for further analysis. Synovial fluid samples were diluted before use in a ratio (1:5) with $1 \times \mathrm{PBS}$ (pH:7.2) to reduce the viscosity and measurement of total protein [43].

\section{Cartilage Samples Collection}

After euthanasia by intravenous injection of thiopental sodium $(25 \mathrm{mg} / \mathrm{kg})$ at three, five, and seven months, articular cartilage samples were collected from the left radiocarpal joint and right radiocarpal joint by transverse cut, then articular surfaces were macroscopically examined, followed by fixation in $10 \%$ neutral formalin buffer for histopathology and immunohistochemistry evaluation.

2.6.2. Assessment of Matrix Metalloproteinases (MMPs) Enzymes Activity by Heparin-Enhanced Substrate Zymography

The total protein concentrations for diluted synovial fluid samples were measured by using the method described by Bradford, 1976 [44].

The activity of MMPs (collagenases; 1, 13 and gelatinases; 2, 9) was detected in $7.5 \%$ gelatin zymography by loading $10 \mu \mathrm{L}$ heparin $(0.3 \mathrm{mg} / \mathrm{mL}$ in $1 \times$ sample buffer without SDS) to lanes within 20-30 min after electrophoresis began [45].

\subsubsection{Western Blot Analysis}

Detection of the COL2A1 protein by western blotting was carried out according to [46]. Briefly, equal amounts of total protein $(30 \mu \mathrm{g})$ from different synovial fluid samples were loaded for each lane and separated by 10\% SDS-PAGE, followed by electroblotting by tank transfer technique to the PVDF membrane. The primary antibody used was polyclonal anti-type II collagen, COL2A1 antibody (Chongqing Biospes, cat\# YPA1669), and HRP-conjugate goat anti-rabbit IgG as a secondary antibody (Chongqing Biospes, cat\#BSA1013). The desired specific bands were developed by using DAB horseradish peroxidase chromogenic kit (Chongqing Biospes, cat\#BWR1069).

Both zymogram gels and western blot membranes were digitally scanned in the true color. The bands' intensities were quantified using my Image analysis software v2.0 (Thermo scientific) after being conversed with the grayscale. For western blot analysis, COL2A1 blots were normalized to the total protein according to Fosang et al. [47].

\subsubsection{Histopathological Examination}

Biopsies from cartilage were collected at different time intervals (three months, five months, and seven months from the start of the experiment) and fixed in 10\% neutral formalin buffer. Fixed samples were then processed by the paraffin embedding technique, sectioned, and stained by hematoxylin and eosin stain and Safranin $\mathrm{O}$. The stained tissue was examined by a light microscope and photographed by Olympus camera (XC30, Tokyo, Japan). The cartilage changes were graded according to the OARSI guidelines [48]. 


\subsubsection{Immunohistochemical Analysis}

Caspase-3 was immunohistochemically stained in paraffin-embedded tissue sections. Briefly, after deparaffinization and rehydration, antigen retrieval was performed and the Caspase-3 primary antibody (Novus Biologicals, Centennial, CO, USA) was applied. The avidin-biotin-peroxidase complex method was then carried out according to the manufacturer's protocol (Novus Biologicals) using diaminobenzidine as a substrate and hematoxylin as counterstain. The percentage area of positively stained tissue was measured using Image J software in three images/samples.

\subsection{Statistical Analysis}

The obtained data were statistically analyzed using the One-Way ANOVA Statistics, version 24.0 software (SPSS Inc., Chicago, IL, USA). Polynomial contrasts, post-hoc Duncan, and descriptive statistics were performed. The level of significance was set at $p \leq 0.05$. The represented values are given as a standard error of the mean (SEM).

\section{Results}

\subsection{Clinical Assessment}

\subsubsection{Evaluation of Lameness}

The animals provoked the highest lameness score (score 3) one-week post OA induction, then lameness decreased gradually with constant score (score1) from the second to the seventh month (Table 1).

Table 1. Lameness score according to American Association of Equine Practitioners (AAEP).

\begin{tabular}{cccccccc}
\hline Experimental Periods & Zero Day & 1st Week & 1st Month & 2nd Month & 3rd Month & 5th Month & 7th Month \\
\hline Lameness score & 0 & 3rd degree & 2nd degree & 1st degree & 1st degree & 1st degree & 1st degree \\
\hline
\end{tabular}

\subsubsection{Radiographical Evaluation}

Radiographical findings revealed, according to OARSI:(1) joint space narrowing, which began to appear at the first month post-induction (grade 1), then gradually increased to be grade 2 at the second and third months, and reached grade 3 by the seventh month; (2) subchondral bone sclerosis, which began to appear from the third month post-injection, until the end of the experiment; (3) marginal osteophytes were observed in the fifth and seventh months, while bone attrition was not observed in the present study (Figure 1 and Table 2).

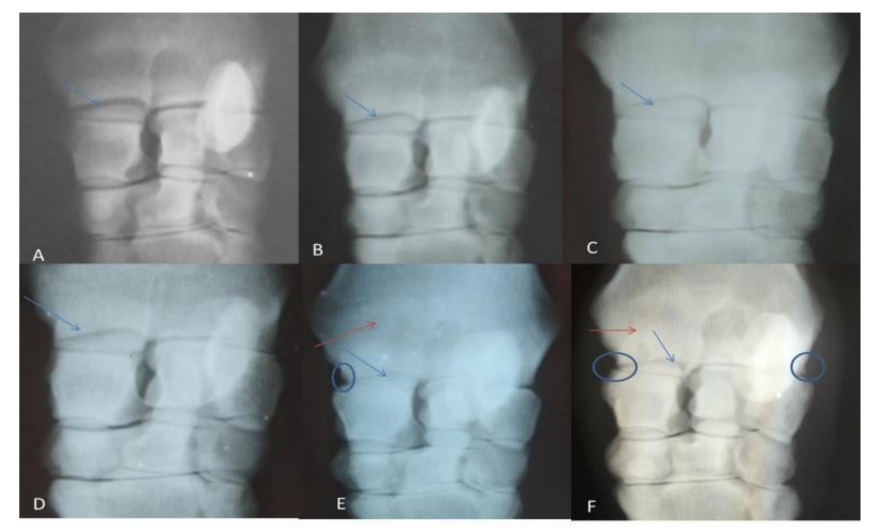

Figure 1. Showing radiographic grading: (A) normal (Day 0), (B) after one month of induction, (C) after 2 months, (D)after 3 months, (E)after 5 months, (F) After 7 months. The radio-carpal joint space showed gradual narrowing (blue arrows), subchondral bone sclerosis (red arrows) and osteophyte appeared in late stages (circle). 
Table 2. Osteoarthritis Research Society International (OARSI) grading scores according to analysis of dorso-palmar radiographs.

\begin{tabular}{cccccccc}
\hline OARSI & Zero Day & 1st Week & 1st Month & 2nd Month & 3rd Month & 5th Month & 7th Month \\
\hline Marginal osteophyte & 0 & 0 & 0 & 0 & 0 & 1 & 1 \\
Joint space narrowing & 0 & 0 & 1 & 2 & 2 & 3 & 3 \\
Sub-chondral sclerosis & Absent & Absent & Absent & Absent & Present & Present & Present \\
Bone attrition & Absent & Absent & Absent & Absent & Absent & Absent & Absent \\
\hline
\end{tabular}

\subsubsection{Ultrasonographic Findings}

The radio-carpal joint at day 0 showed anechoic fluid, smooth articular cartilage, and regular bony alignment. The articular cartilage appeared as two thin echogenic lines above the hyper-echoic surface of the radio-carpal bone. The synovial sac showed that hypo-echoic mass within the synovial fluid was appeared after one month of induction and increased gradually until the third month; this mass decreased in the fifth and seventh months. Articular cartilage showed decreased echogenicity with a defect in its continuity at the seventh month after induction (Figure 2).

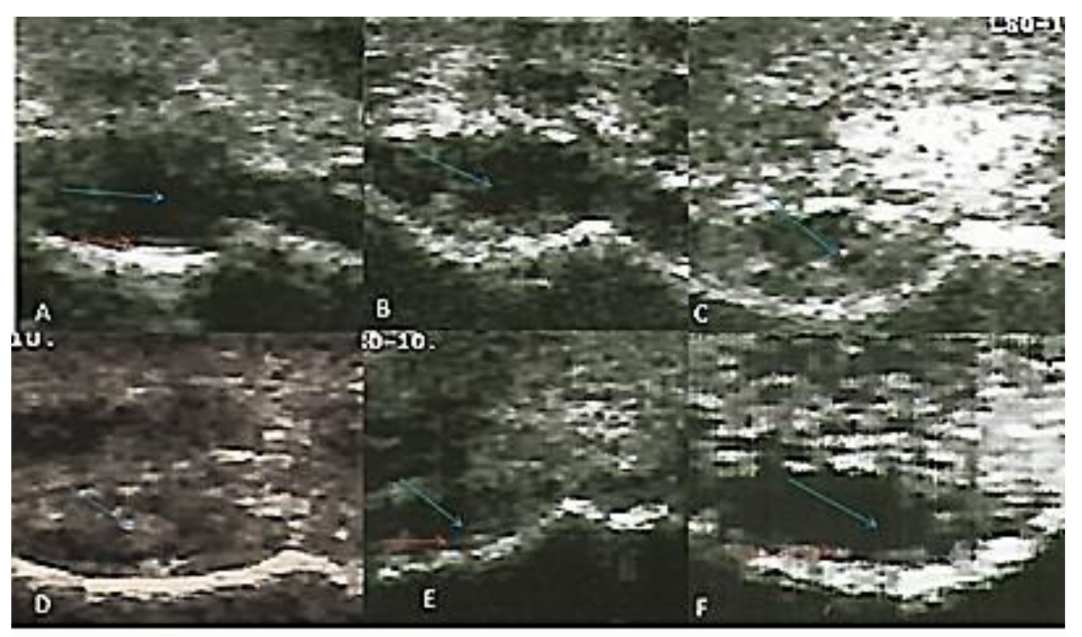

Figure 2. Transverse flexed scan of the radio-carpal joint at (A) day 0, (B) first month, (C) second month, (D) third month, (E) fifth month, (F) seventh month after induction. Synovial sac showed hypo-echoic mass within the synovial fluid (blue arrows). The articular cartilage appeared normal at day 0 and showed a defect in continuity seven months after induction (red arrows).

\subsection{Assessment of Matrixmetalloproteinase Activity}

Collagenase (MMP-1 and MMP-13) and gelatinase (MMP-2 and MMP-9) activities were detected by heparin-enhanced substrate zymography (Figure 3). 


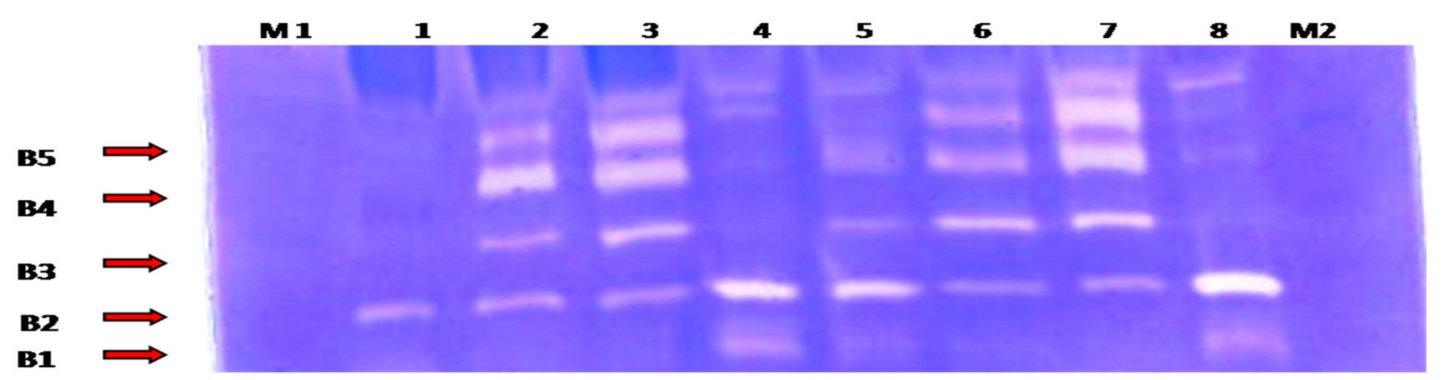

Figure 3. Heparin-enhanced gelatin zymography for MMP activity detection from the synovial fluid samples. Lane 1: represents day 0 (control) samples; lane 2: first week samples; lane 3: first month samples; lane 4: second month samples; lane5: third month samples; lanes 6 and 7: fifth month samples; and lane 8: seventh month samples. B1: corresponding to active MMP13 (48 KDa); B2: active MMP-1(57 KDa); B3: active MMP-2 (66 kDa); B4: active MMP-9 (86 KDa); and B5: latent MMP-9 (92 KDa). M1: pre-stained protein marker (10-175 KDa) (M1 was loaded at the beginning of the electrophoresis, while M2 was loaded 20min after the electrophoresis began).

Collagenase activity for MMP-1 and MMP-13 was found to be expressed in an undulating manner with two peaks of maximum expression detected in the second month and at the seventh month $(p<0.05)$ (Figure 4).

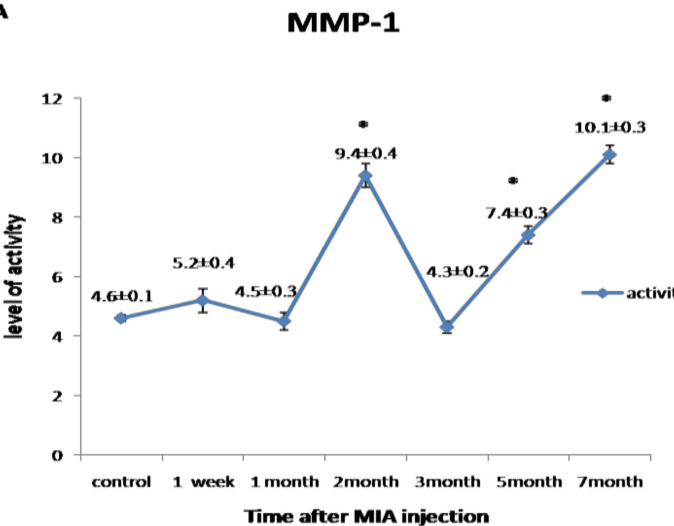

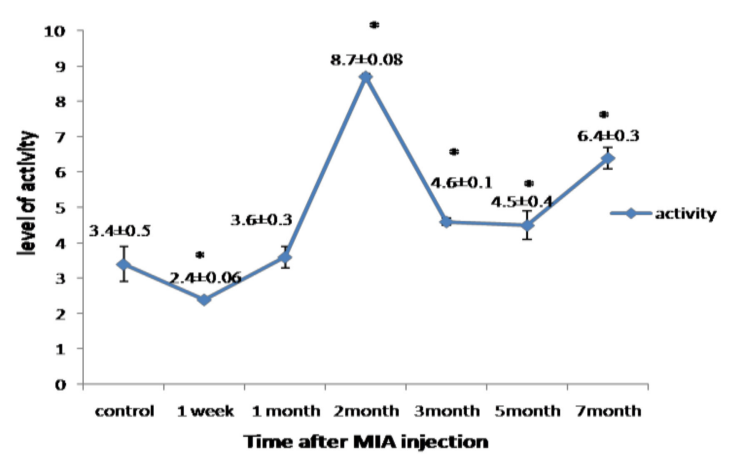

Figure 4. Graphical representation of the changes in the activity of matrix metalloproteinases (MMPs) during the disease progression post-monoiodoacetate (MIA) injection at day 0 , 1st week, 1st month, 2nd month, 3rd month, 5th month, and 7th month. (A) Representing the activity of MMP-1. (B) Representing the activity of MMP-13. All data are represented as (mean \pm SEM) for triplicate samples $(n=3) .{ }^{*}$ denotes a significant difference from control samples at day 0 at $p<0.05$.

Gelatinase activity for MMP-2 and MMP-9 was detected in a biphasic expression pattern; the first phase started from the first week to the first month, which recorded the highest value of its activity. The second phase started from the third to the seventh month. Meanwhile, the latent MMP-9 first phase of expression started from the first week to the second month, and the second phase began from the fifth month to the end of the experiment. The highest level of gelatinases activity was observed in the first month $(p<0.05)$ (Figure 5). 

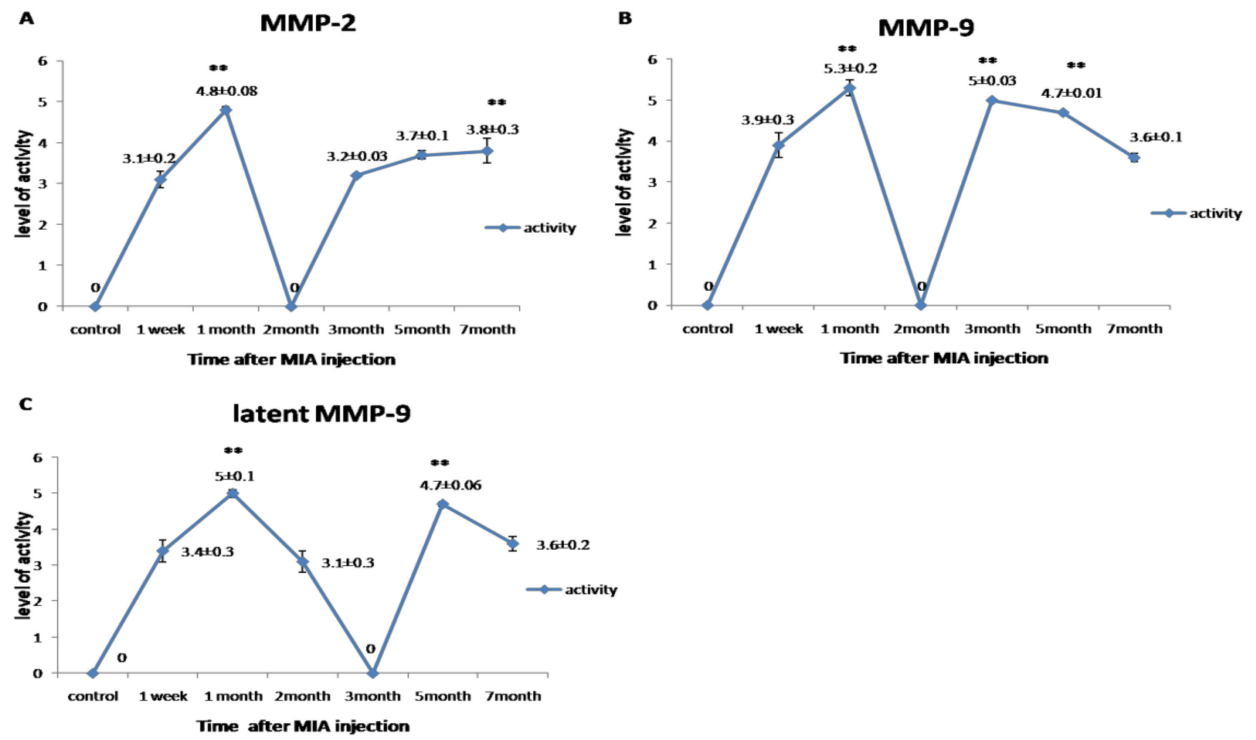

Figure 5. Graphical representation for the changes in the activity of MMPs during the disease progression post-MIA injection at day 0, 1st week, 1st month, 2nd month, 3rd month, 5th month, and 7th month. (A) Representing the activity of MMP-2. (B) Representing the activity of MMP-9. (C) Representing the activity of latent MMP-9. All data are represented as mean \pm SEM for triplicate samples $(n=3)$. ${ }^{* *}$ denotes significant difference from samples in the 1 st week at $p<0.05$.

\subsection{Immunoblot Analysis for COL2A1 Protein}

The western blotting for COL2A1protein revealed single specific bands at molecular weight $\sim 65$ KDa (Figure 6A). The expression level of COL2A1 protein was gradually increased, with a plateau expression pattern starting from the third month until the end of the experiment $(p<0.05)$ (Figure $6 \mathrm{~B}$ ).

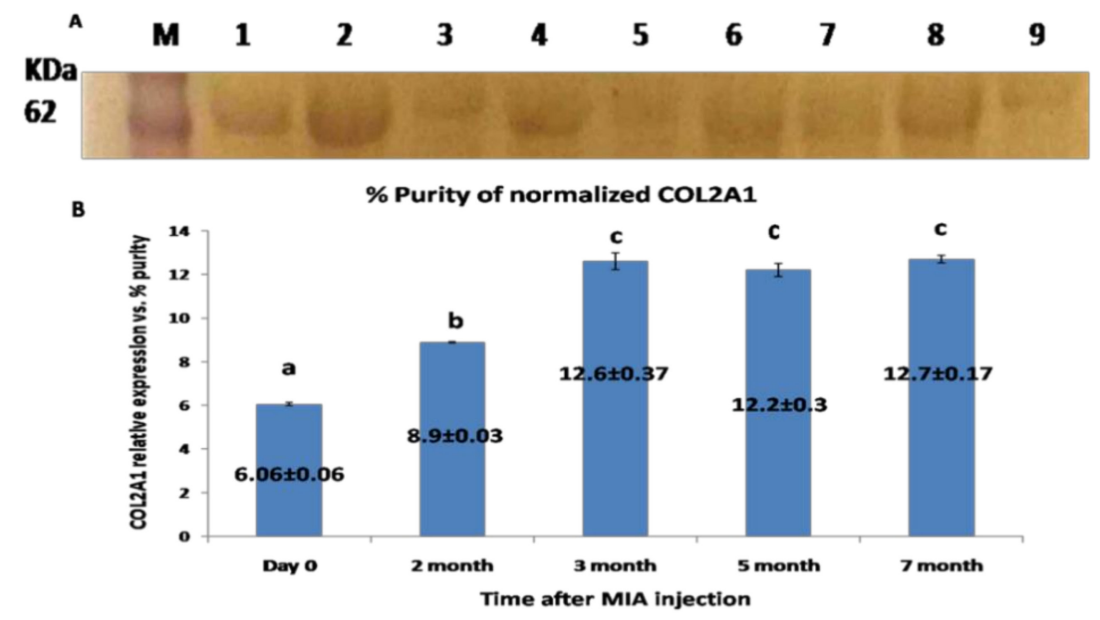

Figure 6. (A) Western blot membrane representing the specific band for COL2A1 protein from the synovial fluid; located at MWT, about $65 \mathrm{KDa}$. (M): pre-stained protein marker; lanes 1, 2 representing samples at day 0 (control); lanes 3, 4 representing samples for the 2nd month; lane 5: samples at the 3rd month; lanes 6 and 7 samples at the 5th month; and lanes 8 and 9 corresponding to the 7 th month. (B) Graphical representation for the level of COL2A1 protein expression level relative to total protein Coomassie blue staining) as quantified by densitometric analysis of the bands. Data presented as the mean \pm SEM for triplicate samples $(n=3)$. Values with the same letters are non-significantly different $(p>0.05)$ while the values of different letters are significantly different $(p<0.05)$. 


\subsection{Macroscopical Findings}

Gross macroscopic examination for the articular cartilage revealed focal erosion at the distal radial articular surface at the seventh month post-MIA induction (Figure 7).

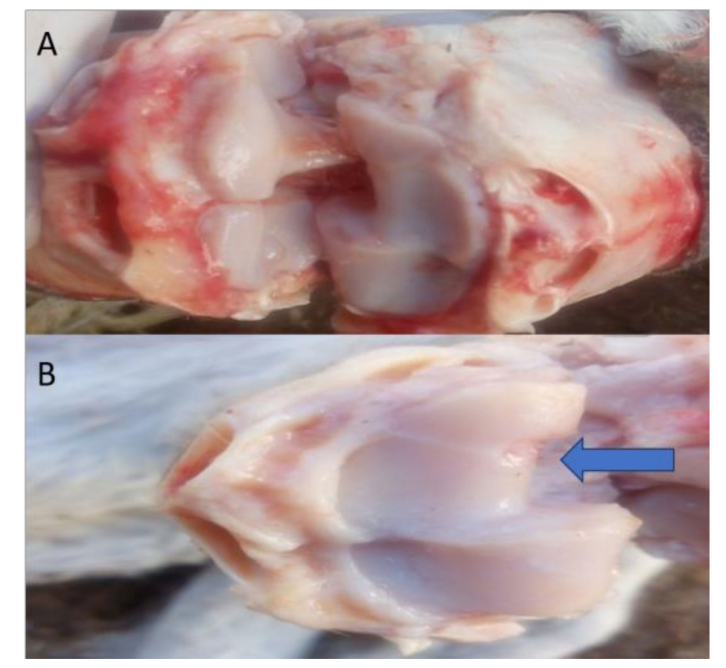

Figure 7. Representative images of the macroscopic observation for the distal articular surface of the radius. (A) Represents the right radiocarpal joint, while (B) Represents the left radiocarpal joint, showing erosions at the distal articular surface of the radius after the 7th month (blue arrow).

\subsection{Histopathological Examination}

Histopathological examination of the articular cartilage in the control group at the third month revealed normal histological features and a smooth surface (Figure 8a), whereas the surface of the articular cartilage became uneven with superficial fibrillation in the treated group (Figure 8b).In the fifth month, the articular cartilage in the control group revealed normal histological structure, in which the matrix and chondrocytes were organized into superficial, mid, and deep zones (Figure 8c). In the MIA-injected group, there was surface fibrillation and vertical branching fissures extended into the mid zone (grade 3) (Figure 8d), which became more severe at the seventh month, resulting in extensive erosion with excavation and loss of matrix in the fissured domains (grade 4) (Figure 8e).

Using Safranin O, the articular cartilage in the control group showed normally distributed chondrocytes and a smooth surface (Figure 9a). In the MIA-injected group after the third month, on the other hand, it demonstrated superficial fibrillation and decreased or variable staining intensity at the surface (Figure 9b). At the fifth month, the articular cartilage revealed an uneven surface and matrix fibrillation became clearer and extended vertically down into the mid-zone with loss of proteoglycans and loss of viable chondrocytes (Figure 9c). In the seventh month, the fissures became more extensive and extended into the deep zone, together with further loss of proteoglycan staining and excavation. Clusters of chondrocyte proliferation were also observed (Figure 9d). 

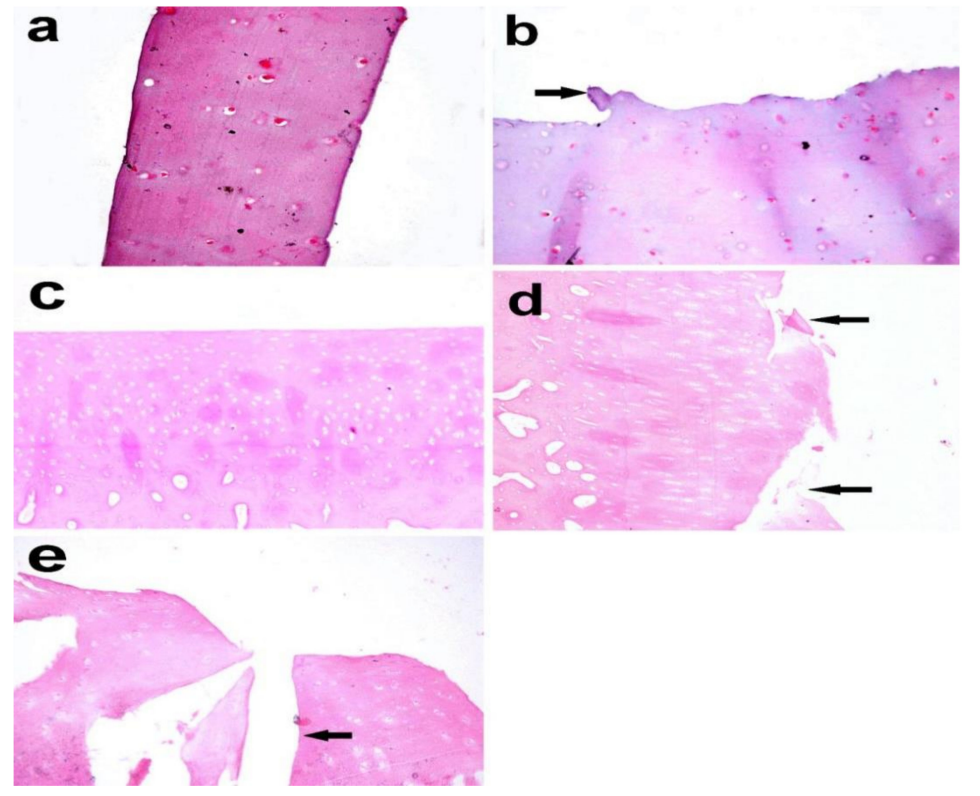

Figure 8. Articular cartilage biopsy of donkey. (a) Normal histologic features and a smooth surface in the control group (right radius articular cartilage), (b) uneven surface with superficial fibrillation (arrow) in theMIA-injected group (left radius articular cartilage) after 3 months (X 400). (c) Normal histological structure in which the matrix and chondrocytes are organized into superficial, mid, and deep zones. (d) Surface fibrillation and vertical branching fissures extending into mid-zone after 5 months (grade 3) (arrow). (e) Extensive erosion with excavation and loss of matrix in fissured domains (grade 4) after 7 months (arrow). (X 200), Haematoxylin and eosin stain.

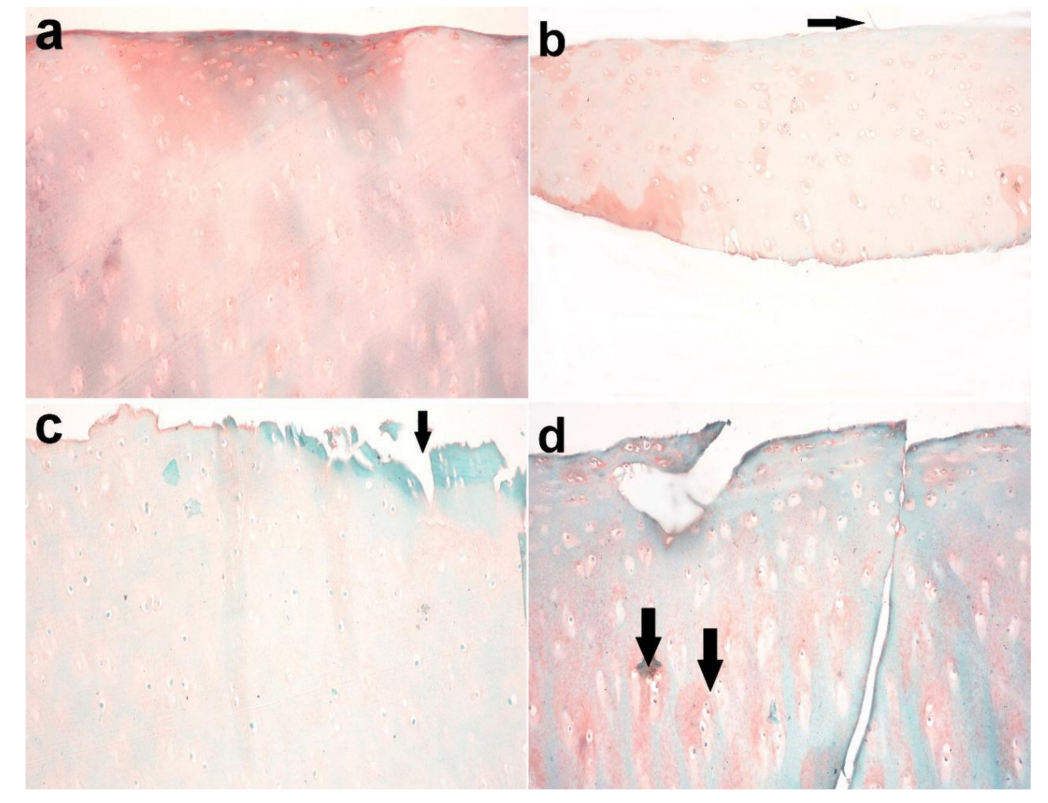

Figure 9. Articular cartilage of donkey. (a) Normal histology of articular cartilage with normally distributed chondrocytes and a smooth surface in the control group (right radius articular cartilage). (b) Superficial fibrillation and decreased or variable staining intensity at the surface in the MIA-injected group after 3 months (arrow). (c) Uneven surface and matrix fibrillation became clearer and extended vertically down into the mid-zone with the loss of proteoglycans and loss of viable chondrocytes in the treated group (arrow) after 5 months. (d) The fissures became more extensive and extended into the deep zone, together with further loss of proteoglycan staining and excavation after 7 months. Note the presence of clusters of chondrocyte proliferation (arrow). Safranin O stain X 200. 


\subsection{Immunohistochemical Analysis}

Immunohistochemical staining of Caspase- 3 in the examined articular cartilage revealed increased expression of Caspase-3 in chondrocytes compared to control. The expression of Caspase-3 increased with an increase in time post-MIA injection (Figures 10 and 11).

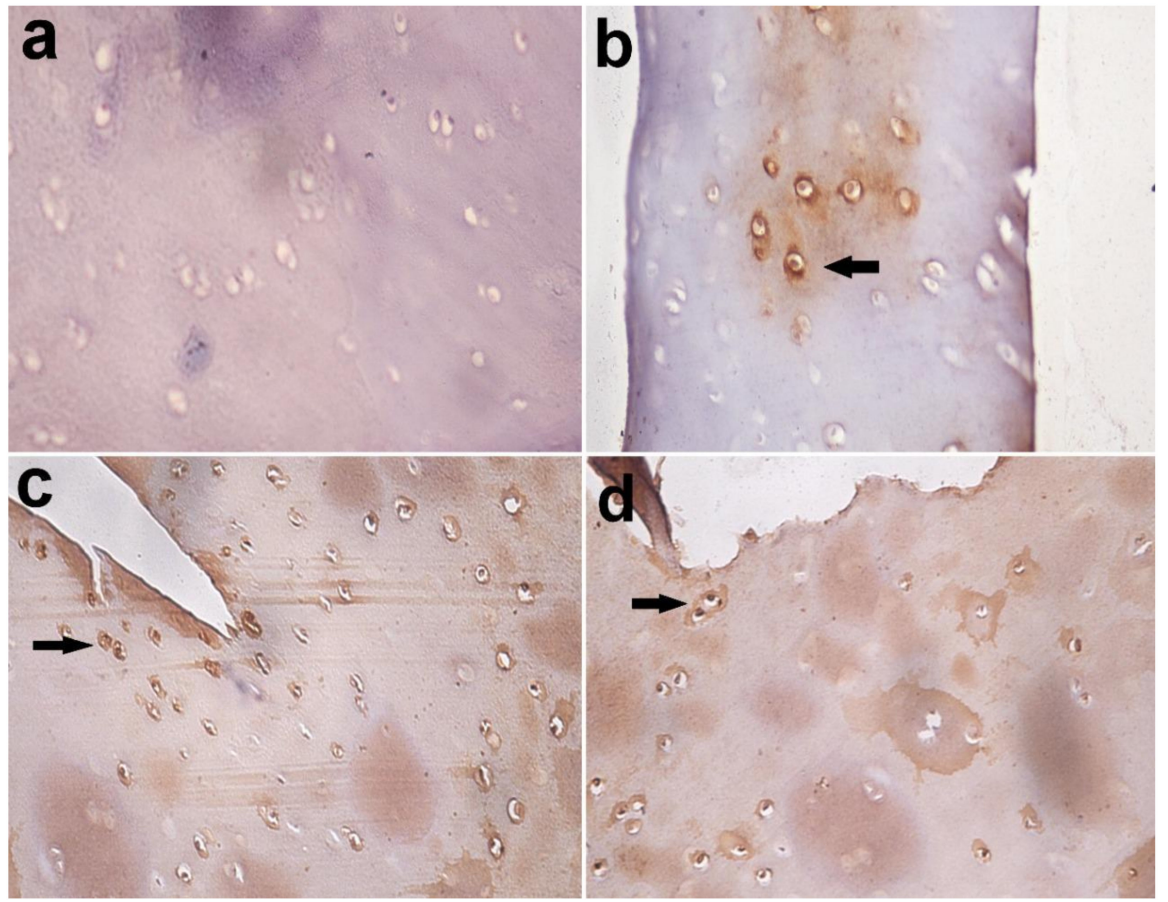

Figure 10. Immunohistochemical staining of Caspase-3 in articular cartilage, equine. (a) Caspase-3 negative chondrocytes in control group; (b) few Caspase-3 positive chondrocytes in the MIA-injected group after 3 months (arrow); (c) many Caspase-3 positive chondrocytes in the MIA-injected group after 5 months; (d) and in MIA-injected group after 7 months (arrow). Immuno-peroxidase stain X 400.

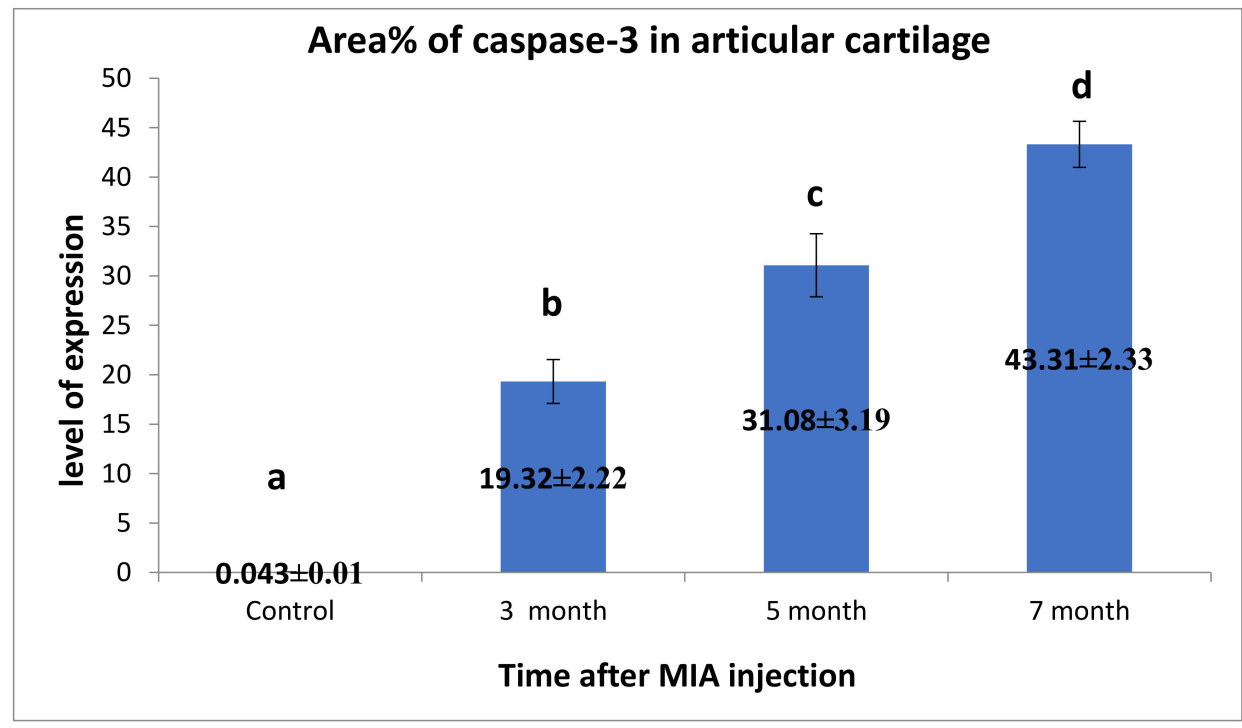

Figure 11. Immunohistochemical analysis for area $\%$ of Caspase-3 in examined articular cartilage revealed increased expression of Caspase- 3 in chondrocytes compared to control. The expression of Caspase-3 increased with the increase of time post-MIA injection. Data presented as the mean \pm SEM for triplicate samples $(n=3)$. Values with the same letters are non-significantly different $(p>0.05)$, while the values of different letters are significantly different $(p<0.05)$. 


\section{Discussion}

Osteoarthritis is considered to be one of the life welfare-threatening diseases of socioeconomic burden for humans and animals [4]. Despite the great economic importance of joint diseases, especially $\mathrm{OA}$ in equine, studies concerning the pathophysiological mechanisms involved in joint degeneration in this species are limited [49].

Little of the literature used donkey as the OA model [32-34], although it is one of the equine species that is phylogenetically and biochemically closest to the horse, in addition to its low price and low cost of feedstuff and housing [34].

The current study traced the progression of clinico-histologic lesions in a chemically-induced osteoarthritic donkey model with major emphasis on MMPs and collagen metabolites.

In the present study, lameness was graded according to AAEP, where the highest score was reached after one week then decreased gradually. These results are in agreement with the previous report [34] that lameness was a major feature for MIA-injected donkeys. Also, Uilenreef et al. (2019) [37] assessed the lameness in MIA-injected pigs, where the animals showed rapid lameness which was greatly declined by the end of the experiment. In-context, MIA injection produced weight-bearing asymmetry in rats; this asymmetry was biphasic, possibly reflecting the initial inflammatory-driven phase of pain, followed by a second chronic phase that is connected to pathomorphological changes in the joint [50-53]. The observed low lameness score as the experiment proceeded in the current study could be due to the usage of a mild dose of MIA $(25 \mathrm{mg})$, which did not induce severe lameness [37,54,55].

Radiographically, the gradual narrowing in the joint space, subchondral bone sclerosis, and osteophytes formation that were recorded in the current study agreed with the previous report [34]. Rat hips injected with MIA showed definite joint space narrowing and deformity of the femoral head, evidenced by a flattened epiphysis [56]. However, radiographical grading for the severity of OA in humans usually does not reflect the amount of inflammation and joint damage, therefore it does not correlate to joint pain $[57,58]$. These findings appeared sound to our findings; by the disease progress, the radiographic osteoarthritic changes were detected, and the lameness score decreased. Bone attrition was not observed in this study, which could be due to the dose of MIA injected, which resulted in mild to moderate osteoarthritic lesions.

Ultrasound recorded the changes in the joint cavity and articular cartilage for the first time in Egyptian donkeys in the present study. A hypo-echoic mass appeared within the synovial fluid after one month of induction and increased gradually until the third month, then decreased at the fifth and seventh months. Articular cartilage showed decreased echogenicity with a defect in its continuity in the seventh month after induction.

Intra-articular MIA injection resulted in synovial membrane hemorrhage with blood effusion, that appeared as an ultrasonographic hypoechoic mass [34]. Moreover, the hypoechoic mass could be due to edema generated by MIA injection [54]. This observed edema is due to acute inflammation, which was dependent on TRPA1(Transient Receptor Potential Ankyrin 1) activation through endogenously-formed reactive oxygen and nitrogen species and their metabolites [59,60].TRPA1 mediates its action through several mechanisms, such as mast cell degranulation, neutrophil migration, the release of histamine, serotonin, and adrenaline in concomitantwith the production of prostaglandins [61,62].Also, it enhances the expression of inflammatory genes, such as prostaglandin-producing enzyme COX-2, myeloperoxidase, and IL1 $\beta$, IL-6, inducible nitric oxide synthase (iNOS), and MMPs [63,64]. Additionally, TRPA1 activation results in pain sensation, amplification of neurogenic inflammation through the release of neuropeptides such as substance $P$ and calcitonin gene related peptide [65,66]. The reduction of inflammatory edema, pain, and lameness score with time in the current work might be due to decrement in TRPA1 expression. This hypothesis needs further study to correlate between the MIA and TRPA1 expression.

Matrix metalloproteinases have been involved in cartilage matrix degradation associated with OA [67]. Their synthesis is tightly regulated at the level of gene expression and in a tissue-specific 
manner [68]. Therefore, it was reasonable to assess MMPs in the synovial fluid of the joint environment [14].

Under normal physiological conditions, the expression of MMPs was low, but increased with the progression of OA, where proinflammatory cytokines such as IL-1 $\beta$ and TNF $\alpha$ are produced by chondrocytes, creating inflammatory processes, resulting in an increase in the synthesis of matrix-degrading proteinases [69].

Heparin-enhanced substrate zymography was used to evaluate the collagenases (MMP-1, MMP-13) and the gelatinases (MMP-2, MMP-9) activities in the synovial fluid for the first time in donkeys. MMP-1 and MMP-13 exhibited an undulating expression pattern, where the activity increased in the second month, then decreased and re-increased in the seventh month, also activity of MMP1 was higher than that of MMP-13. In the same line, Janusz et al. (2001) [70] reported increased activity in the collagenase and gelatinase during the first seven days after iodoacetate injection into rat knees, with a decline in activity at day 21. The level of MMP-1 expression is often 10-fold higher than the level of MMP-13 expression [71]. MMP-13 is associated with pain, disease severity, and pathogenesis of OA [72].

MMP-2 and MMP-9, in the current work, had two phases of up-regulation: peaking in the first month and between the third and seventh months, and the second peak for latent MMP-9 was between the fifth and seventh months. Elevated MMP-2 and MMP-9 activities have been detected in synovial fluid from various joint diseases in man [73-75], but in the equine, few data on synovial gelatinase activities are recorded [76-78]. Interestingly, MMP2 and MMP13 have been found in the active forms. From these data, it can be concluded that the early phase of MIA-induced OA is characterized by a decrease in the biosynthetic activity of cartilage in concomitant with the increase in catabolic activities, followed by a period of compensation where the chondrocytes try to resist the catabolic phase, which was represented in the second month, where the gelatinases activity was down-regulated.

Inline, MMP-2 expression in normal adult cartilage is weak due to very low collagen turnover, and it is upregulated in arthritis $[79,80]$. MMP-2 was strongly expressed in the synovial fluid of the unstable knee in the canine cruciate ligament transaction (ACLT) model of OA from the first day post-surgery, and remained high for eight months, indicating that MMP-2 is responsible for the initiation and progression of OA [81]. MMP-9 protein expressions were higher in the synovial joint fluid of patients with OA [82], and it has been demonstrated to be highly expressed in the early stages of wound healing due to its involvement in angiogenesis [83]. Pajak et al. (2017) [84] added that MMPs' genes transcription was increased in the osteoarthritic rat model, with the highest expression in mRNA for MMP-9, which was firstly increased at day 2 then significantly decreased at day 28 compared to the gradual increase of MMP-13 to day 28. These data in concomitant with our results reveal that gelatinases initiate the degradative sequences in early OA, followed by collagenases, which play a pronounced role in OA progression. Many studies proposed MMP-2 and MMP-9 in synovial fluid as a potential biomarker for the diagnosis of $\mathrm{OA}$ in equine $[1,85]$.

On the other hand, Heard et al. (2012) [14] reported that MMP levels in human knees cannot distinguish between normal and early OA stage, as MMP-1,2,9 and 13 levels appeared to be similar, while in advanced OA they seemed to be detected at a higher level.

In this report, MMP activity differentiated between normal and osteoarthritic synovial fluids, but it could not differentiate between the early and the late stages.

COL2A1 is the major component of the cartilage matrix, and its degradation by MMPs is considered a typical pathological process in OA development [86]. Qualitative immunoblot analysis in the present study recognized the COL2A1 protein as a $65 \mathrm{KDa}$ common band in the synovial fluid, which is different from $140 \mathrm{KDa}$ expected one. Quantitatively, our blot analysis revealed an unexpected significant increase in COL2A1 level of expression along the OA progression, starting from the second month, until the end of the study.

To our knowledge, our study is the first to monitor the expression level of COL2A1 in the synovial fluid of donkeys during the progression of OA. Regarding our surprising results, the authors 
postulate that the polyclonal COL2A1 antibody identified partially degraded forms of type II collagen. This assumption has been strongly raised from studies reporting that type II collagen is cleaved by collagenases (MMP-1,8 and 13), resulting in two fragments: a three-quarter-length fragment $\left(\mathrm{TC}^{\mathrm{A}}\right.$ ) and a one-quarter-length fragment $\left(\mathrm{TC}^{\mathrm{B}}\right)$. As a result of proteolysis, type II collagen epitopes were lost to body fluids, indicating the amount of collagen degradation [87-89]. Since 1989, Moreland et al. [90] has reported the presence of insoluble and partially degraded type II collagen in synovial phagocyte using a well-defined monoclonal antibody against type II collagen. The results of MMP activity where the collagenases (MMP-1 and 13)were detected in the normal synovial fluid at a low level and began to increase from the second month post-induction and the action of collagenase precede the degradation of COL2A1; this strengthens and confirms our speculation about COL2A1 appearance in the synovial fluid. Another explanation may be directed to the osteophyte formation. Osteophyte formation is a process of neochondrogenesis of mesenchymal stem cells (MSC) present in the periosteum at the bone-cartilage junction and is observed at the joint margins [91]. Osteophyte cellular differentiation has been analyzed by investigating collagen expression on mRNA and protein level $[92,93]$. On the mRNA level, it was found that osteophytes are composed of cells that express type I procollagen mRNA, mesenchymal prechondrocytes that express type IIA procollagen mRNA, and maturing chondrocytes that express type IIB procollagen mRNA [94]. On the protein level, Junker et al. (2015) [95] found that collagen II was strongly expressed throughout osteophyte formation. Recently, several studies stated that COL2A1 mRNA expression level was significantly increased in chondrocytes isolated from articular cartilage of high-grade OA patients and proposed that this may be a compensatory anabolic response from the chondrocytes in attempts to restore the ECM $[96,97]$. So, further amino acid sequence assessment of this donkey protein should be performed to confirm these speculations and define the source of collagen II.

To deduce a reliable OA grading, cartilage samples were also used for histopathological and immunohistochemical examination to ensure that synovial fluid can reflect the different status of the articular cartilage.

Histopathological findings using H\&E and Safranin-O stains revealed gradual articular cartilage degeneration until it reached grade 4, according to the OARSI histopathological grading system, as well as chondrocyte proliferation. These results are in agreement with the previous studies on horse $[38,98]$ and human OA [99]. Also, the loss of cartilage proteoglycan, as measured by Safranin O-fast green staining in MIA-induced OA in rats [71] and guinea pigs [36] is due the enzymatic activity of aggrecanase, not MMPs in cartilage cultures stimulated with IL-1. Udo et al. (2016) [100] reported that one of the mechanisms by which MIA induces arthritis is by decreasing proteoglycan content.

Chondrocytes as a sole cell present in cartilage are responsible for the maintenance of the ECM of the cartilage. During the development of OA, chondrocytes change their function and/or undergo apoptosis or chondroptosis [4]. Currently, Immunohistochemical analysis for Caspase-3 in the articular cartilage in the present work revealed a dramatic increase in the expression of Caspase- 3 in chondrocyte in relation to the control samples and reached its highest level after seven months. Inline, overexpression of Caspase-3 has been noted in human OA cartilage, which correlated positively with reduced cell density and apoptosis [101].

Caspase-3 modulated chondrocyte apoptosis and destroyed the structural and biochemical homeostasis in OA [102], while the inhibition of apoptosis using caspase inhibitors reduced the severity of cartilage lesions in experimental OA [103].

MIA is a potent metabolic inhibitor, resulting in the inhibition of glyceraldehyde-3 phosphate dehydrogenase, leading to an increased level of chondrocyte apoptosis [104]. Since this enzyme is involved in the glycolysis pathway and energy production, MIA results in blocking the energy pathways and activation of the intrinsic (mitochondrial) pathway of apoptosis. The intrinsic pathway is mediated by two effectors because of MIA injection. First, by decreasing the mitochondrial energy production resulting in mitochondrial perturbation as alteration and reduction of mitochondrial membrane potential $(\Delta \Psi \mathrm{m})$, which lead to increasing the mitochondrial permeability and release 
of pro-apoptotic factor (cytochrome-c), which results in activation of Caspase-3. The second one through the increased production of ROS, which reduces mitochondrial $\Delta \Psi \mathrm{m}$, and finally both effectors combine and result in the activation of Caspase-3 and apoptosis initiation. Caspase-3 promotes the typical apoptosis features, including DNA fragmentation and cell death, in many tissues, including cartilage [105]. From the obtained results, COL2A1 and Caspase-3 can be considered promising prognostic biomarkers for OA development. Also, they can give an idea about the proper timing for traditional therapeutic intervention by MMP inhibitors, like tetracycline derivatives, which will help in improving the prognosis and reducing the economic losses resulting from such disease.

\section{Conclusions}

Although our study had a limitation concerning the small number of animals used in attempts for the establishment of grading diagnostic biomarkers for the first time in Egyptian donkeys, it would be helpful to extend further work on that socioeconomic disease. The low dose of MIA ( $25 \mathrm{mg} / \mathrm{mL})$ showed the features of OA in donkeys in a time-dependent manner (seven months) and enabled us to follow up and grade the changes for the first time in donkeys. Based on different parameters included in the study, clinical, radiographical, and ultrasonographic examination with MMPs activity, COL2A1 protein expression level, histopathological and immunohistochemical findings, we assumed that OA stages could be graded into: 1-the very early stage (the first month) and characterized by increased the expression of gelatinases; 2-early-stage (represented in the second month) and characterized by the maximum activity of collagenases (MMP-1 and MMP-13) with non-detected activity for gelatinases; 3 -late-stage, starting from the third month, characterized by enhanced activity of all MMPs. Accordingly, therapeutic intervention until the end of the early stage could represent a good prognosis in relation to the levels of COL2A1 and Caspase-3.

Despite the fine regulation for the activity of MMPs, they cannot differentiate between the early and late stages of osteoarthritis and we cannot depend on them as an early diagnostic biomarker. So, our group extended the research to precisely define diagnostic, prognostic early biomarkers depending on the circulating miRNAs and gene-controlled metabolic pathways involved in MIA-induced OA in donkeys.

Author Contributions: Conceptualization, A.M.Y., E.M.G., A.M.E.-B. and H.O.A.; Methodology, A.M.Y., A.I.A. and M.S.K.; Software, A.M.Y. and H.O.A.; Validation, E.M.G.; Formal analysis, A.M.Y., A.I.A. and M.S.K.; Resources, A.M.Y. and E.M.G.; Writing-Original draft preparation, A.M.Y.; Writing-Review and editing, H.O.A., A.I.A., M.S.K., A.M.E.-B. and E.M.G.; Supervision, E.M.G., H.O.A., A.M.E.-B., A.I.A. All authors have read and agreed to the published version of the manuscript.

Funding: This research did not receive any specific grant from funding agencies in the public, commercial, or not-for- profit sectors. And the APC was funded by the authors.

Conflicts of Interest: The authors declare no conflict of interest.

\section{References}

1. Fietz, S.; Einspanier, R.; Hoppner, S.; Hertsch, B.; Bondzio, A. Determination of MMP-2 and -9 activities in synovial fluid of horses with osteoarthritic and arthritic joint diseases using gelatin zymography and immunocapture activity assays. Equine Vet. J. 2008, 40, 266-271. [CrossRef] [PubMed]

2. Glyn-Jones, S.; Palmer, A.J.; Agricola, R.; Price, A.J.; Vincent, T.L.; Weinans, H.; Carr, A.J. Osteoarthritis. Lancet 2015, 386, 376-387. [CrossRef]

3. Karsdal, M.A.; Michaelis, M.; Ladel, C.; Siebuhr, A.S.; Bihlet, A.R.; Andersen, J.R.; Guehring, H.; Christiansen, C.; Bay-Jensen, A.C.; Kraus, V.B. Disease-modifying treatments for osteoarthritis (DMOADs) of the knee and hip: Lessons learned from failures and opportunities for the future. Osteoarthr. Cartil. 2016, 24, 2013-2021. [CrossRef] [PubMed]

4. Charlier, E.; Relic, B.; Deroyer, C.; Malaise, O.; Neuville, S.; Collée, J.; Malaise, M.G.; De Seny, D. Insights on Molecular Mechanisms of Chondrocytes Death in Osteoarthritis. Int. J. Mol. Sci. 2016, 17, 2146. [CrossRef] 
5. McIIwraith, C.W.; Frisbie, D.D.; Kawcak, C.E. The horse as a model of naturally occurring osteoarthritis. Bone Jt. Res. 2012, 1, 297-309. [CrossRef]

6. Musumeci, G.; Castrogiovanni, P.; Trovato, F.M.; Weinberg, A.M.; Al-Wasiyah, M.K.; Alqahtani, M.H.; Mobasheri, A. Biomarkers of Chondrocyte Apoptosis and Autophagy in Osteoarthritis. Int. J. Mol. Sci. 2015, 16, 20560-20575. [CrossRef]

7. Musumeci, G.; Aiello, F.C.; Szychlinska, M.A.; di Rosa, M.; Castrogiovanni, P.; Mobasheri, A. Osteoarthritis in the XXIst century: Risk factors and behaviors that influence disease onset and progression. Int. J. Mol. Sci. 2015, 16, 6093-6112. [CrossRef]

8. Di Rosa, M.; Szychlinska, M.A.; Tibullo, D.; Malaguarnera, L.; Musumeci, G. Expression of CHI3L1 and CHIT1 in osteoarthritic rat cartilage model. A morphological study. Eur. J. Histochem. 2014, 16, 2423. [CrossRef]

9. Kim, H.; Blanco, F. Cell Death and Apoptosis in Osteoarthritic Cartilage. Curr. Drug Targets 2007, 8, 333-345. [CrossRef]

10. Lorenz, H.; Richter, W. Osteoarthritis: Cellular and molecular changes in degenerating cartilage. Prog. Histochem. Cytochem. 2006, 40, 135-163. [CrossRef]

11. Sandell, L.J.; Aigner, T. Articular cartilage and changes in arthritis. An introduction: Cell biology of osteoarthritis. Arthritis Res. 2001, 3, 107-113. [CrossRef] [PubMed]

12. Cawston, T.E.; Wilson, A.J. Understanding the role of tissue degrading enzymes and their inhibitors in development and disease. Best Pract. Res. Clin. Rheumatol. 2006, 20, 983-1002. [CrossRef] [PubMed]

13. Plaas, A.; Osborn, B.; Yoshihara, Y.; Bai, Y.; Bloom, T.; Nelson, F.; Mikecz, K.; Sandy, J.D. Aggrecanolysis in human osteoarthritis: Confocal localization and biochemical characterization of ADAMTS5-hyaluronan complexes in articular cartilages. Osteoarthr. Cartil. 2007, 15, 719-734. [CrossRef] [PubMed]

14. Heard, B.J.; Martin, L.; Rattner, J.B.; Frank, C.B.; Hart, D.A.; Krawetz, R. Matrix metalloproteinase protein expression profiles cannot distinguish between normal and early osteoarthritic synovial fluid BMC. Musculoskelet. Disord. 2012, 13, 126-138. [CrossRef] [PubMed]

15. Smith, N. The role of collagenolytic matrix metalloproteinases in the loss of articular cartilage in osteoarthritis Gerald. Front. Biosci. 2006, 11, 3081-3095. [CrossRef] [PubMed]

16. Hashimoto, S.; Ochs, R.L.; Komiya, S.; Lotz, M. Linkage of chondrocyte apoptosis and cartilage degradation in human osteoarthritis. Arthritis Rheumatol. 1998, 41, 1632-1638. [CrossRef]

17. Kim, H.A.; Suh, D.I.; Song, Y.W. Relationship between chondrocyte apoptosis and matrix depletion in human articular cartilage. J. Rheumatol. 2001, 28, 2038-2045.

18. Mistry, D.; Oue, Y.; Chambers, M.G.; Kayser, M.V.; Mason, R.M. Chondrocyte death during murine osteoarthritis. Osteoarthr. Cartil. 2004, 12, 131-141. [CrossRef]

19. Frisch, S.M.; Screaton, R.A. Anoikis mechanisms. Curr. Opin. Cell Biol. 2001, 13, 555-562. [CrossRef]

20. Hashimoto, S.; Ochs, R.L.; Rosen, F.; Quach, J.; McCabe, G.; Solan, J.; Seegmiller, J.E.; Terkeltaub, R.; Lotz, M. Chondrocyte-derived apoptotic bodies and calcification of articular cartilage. Proc. Natl. Acad. Sci. USA 1998, 95, 3094-3099. [CrossRef]

21. Kuhn, K.; D’Lima, D.D.; Hashimoto, S.; Lotz, M. Cell death in cartilage. Osteoarthr. Cartil. 2004, 12, 1-16. [CrossRef] [PubMed]

22. Thornberry, N.A.; Lazebnik, Y. Caspases: Enemies within. Science 1998, 281, 1312-1316. [CrossRef] [PubMed]

23. May, S.A. Animal models and other experimental system in the investigation of equine arthritis. In Joint Diseases in the Horse; Saunders: Philadelphia, PA, USA, 1996; pp. 421-440.

24. Little, C.B.; Zaki, S. What constitutes an "animal model of osteoarthritis" the need for consensus? Osteoarthr. Cartil. 2012, 20, 261-267. [CrossRef] [PubMed]

25. Malfait, A.-M.; Christopher, B.; Malfait, L. What constitutes an "animal model of osteoarthritis" e the need for consensus? On the predictive utility of animal models of osteoarthritis and Little Arthritis. Res. Ther. 2015, 17, 225-239.

26. Kuyinu, E.L.; Narayanan, G.; Nair, L.S.; Laurencin, C.T. Animal models of osteoarthritis: Classification, update, and measurement of outcomes. J. Orthop. Res. 2016, 11, 19. [CrossRef]

27. Frisbie, D.D.; Cross, M.W.; McIlwraith, C.W. A comparative study of articular cartilage thickness in the stifle of animal species used in human pre-clinical studies compared to articular cartilage thickness in the human knee. Vet. Comp. Orthop. Traumatol. 2006, 19, 142-146. [CrossRef] 
28. Ahern, B.J.; Parvizi, J.; Boston, R.; Schaer, T.P. Preclinical animal models in single site cartilage defect testing: A systematic review. Osteoarthr. Cartil. 2009, 17, 705-713. [CrossRef]

29. Malda, J.; Benders, K.E.; Klein, T.J.; de Grauw, J.C.; Kik, M.J.; Hutmacher, D.W.; Saris, D.B.; van Weeren, P.R.; Dhert, W.J. Comparative study of depth-dependent characteristics of equine and human osteochondral tissue from the medial and lateral femoral condyles. Osteoarthr. Cartil. 2012, 20, 1147-1151. [CrossRef]

30. Hurtig, M. Use of autogenous cartilage particles to create a model of naturally occurring degenerative joint disease in the horse. Equine Orthop. Inj. Repair 1988, 6, 19-22. [CrossRef]

31. Huber, M.J.; Schmotzer, W.B.; Riebold, T.W.; Watrous, B.J.; Synder, S.P.; Von Scott, E.A.; Matthiessen, P.C. Fate and effect of autogenous osteochondral fragments implanted in the middle carpal joint of horses. Am. J. Vet. Res. 1992, 53, 1579-1588.

32. Singh, K.I.; Sobti, V.K.; Roy, K.S. Gross anhistomorphological effects of therapeutic ultrasound in experimental acute traumatic arthritis in donkeys. J. Equine Vet. Sci. 1997, 17, 150-155. [CrossRef]

33. Mokbel, A.N.; El Tookhy, O.S.; Shamaa, A.A.; Rashed, L.A.; Sabry, D.; El Sayed, A.M. Homing and reparative effect of intra-articular injection of autologous mesenchymal stem cells in osteoarthritic animal model. BMC Musculoskelet. Disord. 2011, 12, 259. [CrossRef] [PubMed]

34. Elmesiry, A.; Seleim, M.; Cullis-hill, D. Iodoacetate and allogenous cartilage particles as models for arthritis induction in equine. Int. J. Vet. Sci. Med. 2014, 2, 142-150. [CrossRef]

35. Guzman, R.E.; Evans, M.G.; Bove, S.; Morenko, B.; Kilgore, K. Mono-iodoacetate-induced histologic changes in subchondral bone and articular cartilage of rat femorotibial joints: An animal model of osteoarthritis. Toxicol. Pathol. 2003, 31, 619-624. [CrossRef]

36. Williams, J.; Brandt, K. Benoxaprofen reduces osteophyte formation and fibrillation after articular cartilage injury. J. Rheumatol. 1985, 12, 27-32.

37. Uilenreef, J.; van der Staay, F.J.; Meijer, E. A Monosodium Iodoacetate Osteoarthritis Lameness Model in Growing Pigs. Animals 2019, 9, 405. [CrossRef]

38. Trotter, G.W.; Yovich, J.V.; McIlwraith, C.W.; Norrdin, R.W. Effects of intramuscular polysulfated glycosaminoglycan on chemical and physical defects in equine articular cartilage. Can. J. Vet. Res. $1989,53,224-230$.

39. Gustafson, S.B.; Trotter, G.W.; Norrdin, R.W.; Wrigley, R.H.; Lamar, C. Evaluation of intra-articularly administered sodium monoiodoacetate-induced chemical injury to articular cartilage of horses. Am. J. Vet. Res. 1992, 53, 1193-1202.

40. Boster, C.E.; Burn, C.C.; Barr, A.R.S.; Whay, H.R. The range and prevalence of pathological abnormalities associated with lameness in working horses from developing countries. Equine Vet. J. 2009, 41, 474-481. [CrossRef]

41. Reix, C.E.; Burn, C.C.; Pritchard, J.C.; Barr, A.R.; Whay, H.R. The range and prevalence of clinical signs and conformation associated with lameness in working draught donkeys in Pakistan. Equine Vet. J. 2014, 46, 771-777. [CrossRef]

42. Altman, R.D.; Gold, G.E. Atlas of individual radiographic features in osteoarthritis. Osteoarthr. Cartil. 2007, 15, A1-A56. [CrossRef] [PubMed]

43. Ryu, J.H.; Lee, A.; Huh, M.S.; Chu, J.; Kim, K.; Kim, B.; Choi, K.; Kwon, I.C.; Park, J.W.; Youn, I. Measurement of MMP Activity in Synovial Fluid in Cases of Osteoarthritis and Acute Inflammatory Conditions of the Knee Joints Using a Fluorogenic Peptide Probe-Immobilized Diagnostic Kit. Theranostics 2012, 2, 198-206. [CrossRef] [PubMed]

44. Bradford, M.M. A rapid and sensitive method for the quantitation of microgram quantities of protein utilizing the principle of protein-dye binding. Anal. Biochem. 1976, 72, 248-254. [CrossRef]

45. Yu, W.H.; Woessner, J.F. Heparin-Enhanced Zymographic Detection of Matrillysin and Collagenases. Anal. Biochem. 2001, 293, 38-42. [CrossRef]

46. Yassin, A.M.; Abdel Hamida, M.I.; Farid, O.A.; Amera, H.; Wardaa, M. Dromedary milk exosomes as mammary transcriptome nano-vehicle: Their isolation, vesicular and phospholipidomic characterizations. J. Adv. Res. 2016, 7, 749-756. [CrossRef]

47. Fosang, A.J.; Roger, J.; Colbran, R.J. Transparency is the key to quality. J. Biol. Chem. 2015, 290, $29692-29694$. [CrossRef]

48. Pritzker, K.P.; Gay, S.; Jimenez, S.A.; Ostergaard, K.; Pelletier, J.P.; Revell, P.A.; Salter, D.; van den Berg, W.B. Osteoarthritis cartilage histopathology: Grading and staging. Osteoarthr. Cartil. 2006, 14, 13-29. [CrossRef] 
49. Schlueter, A.E.; Orth, M.W. Equine osteoarthritis: A brief review of the disease and its causes. Equine Comp. Exerc. Physiol. 2004, 1, 221-231. [CrossRef]

50. Fernihough, J.; Gentry, C.; Malcangio, M.; Fox, A.; Rediske, J.; Pellas, T.; Kidd, B.; Bevan, S.; Winter, J. Pain related behavior in two models of osteoarthritis in the rat knee. Pain 2004, 112, 83-93. [CrossRef]

51. Pomonis, J.D.; Boulet, J.M.; Gottshall, S.L.; Phillips, S.; Sellers, R.; Bunton, T.; Walker, K. Development and pharmacological characterization of a rat model of osteoarthritis pain. Pain 2005, 114, 339-346. [CrossRef]

52. Mapp, P.I.; Sagar, D.R.; Ashraf, S.; Burston, J.J.; Suri, S.; Chapman, V.; Walsh, D.A. Differences in structural and pain phenotypes in the sodium monoiodoacetate and meniscal transection models of osteoarthritis. Osteoarthr. Cartil. 2013, 21, 1336-1345. [CrossRef] [PubMed]

53. Moilanen, L.J.; Hamainen, M.; Nummenmaa, E.; Ilmarinen, P.; Vuolteenaho, K.; Nieminen, R.M.; Lehtimaki, L.; Moilanen, E. Monosodium iodoacetate-induced inflammation and joint pain are reduced in TRPA1 deficient mice e potential role of TRPA1 in osteoarthritis. Osteoarthr. Cartil. 2015, 23, 2017-2026. [CrossRef] [PubMed]

54. Dowling, B.; Dart, A.; Matthews, S. Chemical arthrodesis of the distal tarsal joints using sodium monoiodoacetate in 104 horses. Aust. Vet. J. 2004, 82, 38-42. [CrossRef] [PubMed]

55. Goranov, N. Clinical changes in sodium monoiodoacetate induced stifle osteoarthritis model in dogs. Vet. World 2012, 5, 138-144. [CrossRef]

56. Miyamoto, S.; Nakamura, J.; Ohtori, S.; Orita, S.; Omae, T.; Nakajima, T.; Suzuki, T.; Takahashi, K. Intra-articular injection of mono-iodoacetate induces osteoarthritis of the hip in rats. BMC Musculoskelet. Disord. 2016, 17, 132-139. [CrossRef]

57. Dieppe, P.A.; Lohmander, L.S. Pathogenesis and management of pain in osteoarthritis. Lancet 2005, 365, 965-973. [CrossRef]

58. Arendt-Nielsen, L.; Egsgaard, L.L.; Petersen, K.K.; Eskehave, T.N.; Graven-Nielsen, T.; Hoeck, H.C.; Simonsen, O. A mechanism-based pain sensitivity index to characterize knee osteoarthritis patients with different disease stages and pain levels. Eur. J. Pain 2015, 19, 1406-1417. [CrossRef]

59. Yoshida, T.; Inoue, R.; Morii, T.; Takahashi, N.; Yamamoto, S.; Hara, Y.; Tominaga, M.; Shimizu, S.; Sato, Y.; Mori, Y. Nitric oxide activates TRPchannels by cysteine S-nitrosylation. Nat. Chem. Biol. 2006, 2, 596-607. [CrossRef]

60. Andersson, D.A.; Gentry, C.; Moss, S.; Bevan, S. Transient receptor potential A1 is a sensory receptor for multiple products of oxidative stress. J. Neurosci. 2008, 28, 2485-2494. [CrossRef]

61. Moilanen, L.J.; Laavola, M.; Kukkonen, M.; Korhonen, R.; Leppanen, T.; Hogestatt, E.D.; Zygmunt, P.M.; Nieminen, R.M.; Moilanen, E. TRPA1 contributes to the acute inflammatory response and mediates carrageenan-induced paw edema in the mouse. Sci. Rep. 2012, 2, 380. [CrossRef]

62. Perin-Martins, A.; Teixeira, J.M.; Tambeli, C.H.; Parada, C.A.; Fischer, L. Mechanisms underlying transient receptor potential ankyrin 1 (TRPA1)-mediated hyperalgesia and edema. J. Peripher. Nerv. Syst. 2013, 18, 62-74. [CrossRef] [PubMed]

63. Dumond, H.; Presle, N.; Pottie, P.; Pacquelet, S.; Terlain, B.; Netter, P.; Gepstein, A.; Livne, E.; Jouzeau, J.Y. Site-specific changes in gene expression and cartilage metabolism during early experimental osteoarthritis. Osteoarthr. Cartil. 2004, 12, 284-295. [CrossRef]

64. Lee, J.; Hong, Y.S.; Jeong, J.H.; Yang, E.J.; Jhun, J.Y.; Park, M.K.; Jung, Y.O.; Min, J.K.; Kim, H.Y.; Park, S.H.; et al. Coenzyme Q10 ameliorates pain and cartilage degradation in a rat model of osteoarthritis by regulating nitric oxide and inflammatory cytokines. PLoS ONE 2013, 8, 69362. [CrossRef]

65. Bautista, D.M.; Pellegrino, M.; Tsunozaki, M. TRPA1: A gatekeeper for inflammation. Annu. Rev. Physiol. 2013, 75, 181-200. [CrossRef]

66. Zygmunt, P.M.; Hogestatt, E.D. TRPA1. Handb. Exp. Pharmacol. 2014, 222, 583-630. [PubMed]

67. Akhtar, N.; Khana, N.M.; Ashrufa, O.; Haqqia, T.M. Inhibition of cartilage degradation and suppression of PGE2 and MMPs expression by Pomegranate Fruit Extract in a model of Post-Traumatic Osteoarthritis. Nutr. J. 2017, 33, 1-13. [CrossRef] [PubMed]

68. Vincenti, M.P.; White, L.A.; Schroen, D.J.; Benbow, U.; Brinckerhoff, C.E. Regulating expression of the gene for matrix metalloproteinase-1 (collagenase): Mechanisms that control enzyme activity, transcription, and mRNA stability. Crit. Rev. Eukaryot. Gene Expr. 1996, 6, 391-411. [CrossRef]

69. Pelletier, J.P.; Martel-Pelletier, J.; Abramson, S.B. Osteoarthritis, an inflammatory disease: Potential implications for the selection of new therapeutic targets. Arthritis Rheumatol. 2001, 44, 1237-1247. [CrossRef] 
70. Janusz, M.J.; Hookfin, E.B.; Heitmeyer, S.A.; Woessner, J.F.; Freemont, A.J.; Hoyland, J.A.; Brown, K.K.; Hsieh, L.C.; Almstead, N.G.; De, B.; et al. Moderation of iodoacetate-induced experimental osteoarthritis in rats by matrix metalloproteinase inhibitors. Osteoarthr. Cartil. 2001, 9, 751-760. [CrossRef]

71. Elliott, S.; Hays, E.; Mayor, M.; Sporn, M.; Vincenti, M. The triterpenoid CDDO inhibits expression of matrix metalloproteinase-1, matrix metalloproteinase-13 and Bcl-3in primary human chondrocytes. Arthritis Res. Ther. 2003, 5, 285-291. [CrossRef]

72. Wang, M.; Sampson, E.R.; Jin, H.; Li, J.; Ke, Q.H.; Im, H.-J.; Chen, D. MMP13 is a critical target gene during the progression of osteoarthritis. Arthritis Res. Ther. 2013, 15, R5. [CrossRef] [PubMed]

73. Makowski, G.S.; Ramsby, M.L. Zymographic analysis of latent and activated forms of matrix metalloproteinase-2 and -9 in synovial fluid: Correlation to polymorphonuclear leukocyte infiltration and in response to infection. Clin. Chem. Acta 2003, 329, 77-81. [CrossRef]

74. Marini, S.; Fasciglione, G.F.; Monteleone, G.; Maiotti, M.; Tarantino, U.; Coletta, M. A correlation between knee cartilage degradation observed by arthroscopy and synovial proteinases activities. Clin. Biochem. 2003, 36, 295-304. [CrossRef]

75. Peake, N.J.; Foster, H.E.; Khawaja, K.; Cawston, T.E.; Rowan, A.D. Assessment of the clinical significance of gelatinase activity in patients with juvenile idiopathic arthritis using quantitative protein substrate zymography. Ann. Rheum. Dis. 2006, 65, 501-507. [CrossRef]

76. Clegg, P.D.; Coughlan, A.R.; Riggs, C.M.; Carter, S.D. Matrix metalloproteinases 2 and 9 in equine synovial fluids. Equine Vet. J. 1997, 29, 343-348. [CrossRef]

77. Jouglin, M.; Robert, C.; Valette, J.P.; Gavard, F.; Quintin-Colonna, F.; Denoix, J.M. Metalloproteinases and tumor necrosis factor-alpha activities in synovial fluids of horses: Correlation with articular cartilage alterations. Vet. Res. 2000, 31, 507-515. [CrossRef]

78. Trumble, T.N.; Trotter, G.W.; Oxford, J.R.; McIlwraith, C.W.; Cammarata, S.; Goodnight, J.L.; Billinghurst, R.C.; Frisbie, D.D. Synovial fluid gelatinase concentrations and matrix metallo- proteinase and cytokine expression in naturally occurring joint disease in horses. Am. J. Vet. Res. 2001, 62, 1467-1477. [CrossRef]

79. Salo, T.; Makela, M.; Kylmaniemi, M.; Autio-Harmainen, H.; Larjava, H. Expression of matrix metalloproteinase-2 and-9 during early human wound healing. Lab. Invest. 1994, 70, 176-182.

80. Salminen, H.J.; Säämänen, A.-M.K.; Vankemmelbeke, M.N.; Auho, P.K.; Perälä, M.P.; Vuorio, E.I. Differential expression patterns of matrix metalloproteinases and their inhibitors during development of osteoarthritis in a transgenic mouse model. Ann. Rheum. Dis. 2002, 61, 591-597. [CrossRef]

81. Yu, L.P.; Smith, G.N.; Brandt, K.D.; Myers, S.L.; O'Connor, B.L.; Brandt, D.A. Reduction of the severity of canine osteoarthritis by prophylactic treatment with oral doxycycline. Arthritis Rheumatol. 1992, 35, 1150-1159. [CrossRef]

82. Zeng, G.Q.; Chen, A.B.; Li, W.; Song, J.H.; Gao, C.Y. High MMP-1, MMP-2, and MMP-9 protein levels in osteoarthritis. Genet. Mol. Res. 2015, 14, 14811-14822. [CrossRef] [PubMed]

83. Little, C.B.; Barai, A.; Burkhardt, D.; Smith, S.M.; Fosang, A.J.; Werb, Z.; Shah, M.; Thompson, E.W. Matrixmetalloproteinase 13-deficient mice are resistant to osteoarthritic cartilage erosion but not chondrocyte hypertrophy or osteophyte development. Arthritis Rheumatol. 2009, 60, 3723-3733. [CrossRef] [PubMed]

84. Pajak, A.; Kostrzewa, M.; Malek, N.; Korostynski, M.; Starowicz, K. Expression of matrix metalloproteinases and components of the endocannabinoid system in the knee joint are associated with biphasic pain progression in a rat model of osteoarthritis. J. Pain Res. 2017, 10, 1973-1989. [CrossRef] [PubMed]

85. Rorovik, A.M.; Grondahl, A.M. Markers of osteoarthritis: A review of the literature. Vet. Surg. 1995, 24, 255-262. [CrossRef] [PubMed]

86. Lian, C.; Wang, X.; Qiu, X.; Wu, Z.; Gao, B.; Liu, L.; Liang, G.; Zhou, H.; Yang, X.; Peng, Y.; et al. Collagen type II suppresses articular chondrocyte hypertrophy and osteoarthritis progression by promoting integrin ß1-SMAD1 interaction. Bone Res. 2019, 7, 8. [CrossRef] [PubMed]

87. Billinghurst, R.C.; Dahlberg, L.; Ionescu, M.; Reiner, A.; Bourne, R.; Rorabeck, C.; Mitchell, P.; Hambor, J.; Diekmann, O.; Tschesche, H.; et al. Enhanced cleavage of type II collagen by collagenases in osteoarthritic articular cartilage. J. Clin. Invest. 1997, 99, 1534-1545. [CrossRef] [PubMed]

88. Nelson, F.; Dahlberg, L.; Laverty, S.; Reiner, A.; Pidoux, I.; Ionescu, M.; Fraser, G.L.; Brooks, E.; Tanzer, M.; Rosenberg, L.C.; et al. Evidence for altered synthesis of type II collagen in patients with osteoarthritis. J. Clin. Invest. 1997, 102, 2115-2125. [CrossRef] [PubMed] 
89. Birmingham, J.D.; Vilim, V.; Kraus, V.B. Collagen Biomarkers for Arthritis Applications. Biomark. Insights 2006, 1, 61-76. [CrossRef]

90. Moreland, L.W.; Gay, R.E.; Huang, G.Q.; Mcgee, N.; Gay, S. Immunohistologic Demonstration of Type I1 Collagen in Synovial Fluid Phagocytes of Osteoarthritis and Rheumatoid Arthritis Patients. Arthritis Rheumatol. 1989, 32, 1458-1464. [CrossRef]

91. Van der Kraan, P.M.; van den Berg, W.B. Osteophytes: Relevance and biology. Osteoarthr. Cartil. 2007, 15, 237-244. [CrossRef]

92. Aigner, T.; Dietz, U.; Stoss, H.; von der, M.K. Differential expression of collagen types I, II, III, and X in human osteophytes. Lab. Invest. 1995, 73, 236-243. [PubMed]

93. Matyas, J.R.; Sandell, L.J.; Adams, M.E. Gene expression of type II collagens in chondro-osteophytes in experimental osteoarthritis. Osteoarthr. Cartil. 1997, 5, 99-105. [CrossRef]

94. Hashimoto, S.; Creighton-Achermann, L.; Takahashi, K.; Amiel, D.; Coutts, R.D.; Lotz, M. Development and regulation of osteophyte formation during experimental osteoarthritis. Osteoarthr. Cartil. 2002, 10, 180-187. [CrossRef] [PubMed]

95. Junker, S.; Krumbholz, G.; Frommer, K.W.; Rehart, S.; Steinmeyer, J.; Rickert, M.; Schett, G.; Müller-Ladner, U.; Neumann, E. Differentiation of osteophyte typesin osteoarthritis-proposal of a histological classification. Jt. Bone Spine 2016, 83, 63-67. [CrossRef] [PubMed]

96. Imagawa, K.; de Andrés, M.C.; Hashimoto, K.; Itoi, E.; Otero, M.; Roach, H.I.; Goldring, M.B.; Oreffo, R.O. Association of reduced type IX collagen gene expression in human osteoarthritic chondrocytes with epigenetic silencing by DNA hypermethylation. Arthritis Rheumatol. 2014, 66, 3040-3051. [CrossRef] [PubMed]

97. Budd, E.; de Andrées, M.C.; Sanchez-Eisner, T.; Oreffo, R.O.C. MiR-146b is down-regulated during the chondrogenic differentiation of human bone marrow derived skeletal stem cells and up-regulated in osteoarthritis. Sci. Rep. 2017, 7, 46704. [CrossRef] [PubMed]

98. Yovich, J.V.; Turner, A.S.; Stashak, T.S.; MacIllwraith, C.W. Luxation of the metacarpophalangeal and metatarsophalangeal joints in horses. Equine Vet. J. 1987, 19, 295-298. [CrossRef]

99. Guingamp, C.; Gegout-Pottie, P.; Philippe, L.; Terlain, B.; Netter, P.; Gillet, P. Mono-iodoacetate-induced experimental osteoarthritis: A dose-response study of loss of mobility, morphology, and biochemistry. Arthritis Rheumatol. 1997, 40, 1670-1679. [CrossRef]

100. Udo, M.; Muneta, T.; Tsuji, K.; Ozeki, N.; Nakagawa, Y.; Ohara, T.; Saito, R.; Yanagisawa, K.; Koga, H.; Sekiya, I. Monoiodoacetic acid induces arthritis and synovitis in rats in a dose- and time-dependent manner: Proposed model-specific scoring systems. Osteoarthr. Cartil. 2016, 24, 1284-1291. [CrossRef]

101. Sharif, M.; Whitehouse, A.; Sharman, P.; Perry, M.; Adams, M. Increased apoptosis in human osteoarthritic cartilage corresponds to reduced cell density and expression of caspase-3. Arthritis Rheumatol. 2004, 50, 507-515. [CrossRef]

102. Green, D.R.; Llambi, F. Cell Death Signaling. Cold Spring Harb. Perspect. Biol. 2015, 7, a006080. [CrossRef] [PubMed]

103. D’Lima, D.; Hmida, J.; Hashimoto, S.; Colwell, C.; Lotz, M. Caspase inhibitors reduce severity of cartilage lesions in experimental osteoarthritis. Arthritis Rheumatol. 2006, 54, 1814-1821. [CrossRef] [PubMed]

104. Jiang, L.; Li, L.; Geng, C.; Gong, D.; Jiang, L.; Ishikawa, N.; Kajima, K.; Zhong, L. Monosodium iodoacetate induces apoptosis via the mitochondrial pathway involving ROS production and caspase activation in rat chondrocytes in vitro. J. Orthop. Res. 2013, 31, 364-369. [CrossRef] [PubMed]

105. Giunta, S.; Castorina, A.; Marzagalli, R.; Szychlinska, M.A.; Pichler, K.; Mobasheri, A.; Musumeci, G. Ameliorative effects of PACAP against cartilage degeneration. Morphological, immunohistochemical and biochemical evidence from in vivo and in vitro models of rat osteoarthritis. Int. J. Mol. Sci. 2015, 16, 5922-5944. [CrossRef] [PubMed]

(C) 2020 by the authors. Licensee MDPI, Basel, Switzerland. This article is an open access article distributed under the terms and conditions of the Creative Commons Attribution (CC BY) license (http://creativecommons.org/licenses/by/4.0/). 